\title{
HAAG, Norbert, HOLTZ, Sabine, ZIMMERMANN, Wolfgang, Ländliche Frömmigkeit. Konfessionskulturen und Lebenswelten 1500-1850
}

\section{Christophe Duhamelle}

\section{OpenEdition}

\section{Journals}

Édition électronique

URL : http://journals.openedition.org/ifha/1188

DOI : $10.4000 /$ ifha. 1188

ISSN : 2198-8943

Éditeur

IFRA - Institut franco-allemand (sciences historiques et sociales)

Référence électronique

Christophe Duhamelle, «HAAG, Norbert, HOLTZ, Sabine, ZIMMERMANN, Wolfgang, Ländliche Frömmigkeit. Konfessionskulturen und Lebenswelten 1500-1850», Revue de l'IFHA [En ligne], Date de recension, mis en ligne le 01 janvier 2002, consulté le 22 septembre 2020. URL : http:// journals.openedition.org/ifha/1188; DOI : https://doi.org/10.4000/ifha.1188

Ce document a été généré automatiquement le 22 septembre 2020.

(CIFHA 


\title{
HAAG, Norbert, HOLTZ, Sabine, ZIMMERMANN, Wolfgang, Ländliche Frömmigkeit. Konfessionskulturen und Lebenswelten 1500-1850
}

\author{
Christophe Duhamelle
}

Issu d'un colloque tenu en mai 2000 et dirigé par trois élèves de H.-C. Rublack, ce recueil aborde un terrain encore peu exploré par la recherche allemande : celui de la vie religieuse dans les campagnes. Cette relative désaffection s'explique par les difficultés que présente l'accès aux sources, mais aussi par la supposition, héritée du discours des autorités, que les masses rurales obéissaient sans imagination, ou se cantonnaient dans des superstitions rétrogrades. L'évolution des recherches sur la confessionnalisation vers une conception plus balancée des interactions entre « le haut " et " le bas " suscite cependant sur ce thème des études nouvelles dont cet ouvrage donne un bon aperçu. Il en reflète aussi les points forts, d'une part parce que sept contributions sur seize traitent des catholiques et quatre autres de zones mixtes (les études sur la confessionnalisation catholique se sont en effet intéressées précocement au domaine rural), d'autre part parce qu'aucun des articles ne concerne une région située au nord et à l'est d'une ligne Brême-Nuremberg, tandis que six d'entre eux sont consacrés à la Souabe (dont quatre au Wurtemberg) et cinq à la Suisse. L'Est de l'Elbe est un terrain privilégié pour le renouveau des études rurales en Allemagne, mais pas encore dans le domaine religieux.

2 Un thème domine la première partie du livre : l'avènement des Réformes n'a pu s'effectuer que par une négociation avec les communes rurales, qui disposaient non seulement de moyens de pression et de résistance, mais aussi d'une conception propre de leur vie religieuse et du rôle du clergé local - conception qu'elles surent à la fois conserver et adapter. S. DIXON montre ainsi que l'introduction de la Réforme en Brandebourg-Ansbach-Kulmbach (Franconie) s'est jouée avant tout sur le terrain des rapports de force politiques, même si le discours communal dut intégrer la nouvelle 
donne pour pouvoir être entendu. À Lützelburg, village partagé entre la ville d'Augsbourg et le margraviat habsbourgeois de Burgau, la commune fait preuve d'une vigueur comparable dans son choix du protestantisme, même si elle ne peut empêcher la recatholicisation de 1608 (D. SCHIERSNER). C'est sans doute en Suisse que cette promotion du rôle des communes, entamée à la fin du Moyen Âge, s'exprime à l'occasion des Réformes avec la plus grande intensité ; dans les Grisons, le clergé rural est de plus en plus contrôlé par les communes (I. SAULLE HIPPENMEYER) et la biconfessionnalité engendre une complexité originale des pratiques, dont le répertoire va des expériences partagées aux signes distinctifs et comprend de nombreuses transgressions de la frontière confessionnelle (F. VOLKLAND). Dans ce contexte, la place du pasteur et celle du curé demandent à être redéfinies : ils sont certes acteurs du renouveau mais ce dernier, engendrant à la fois une distance accrue envers les ouailles et une coopération multipliée avec elles, contraint le clergé à s'insérer dans le monde du village pour pouvoir délivrer son message et jouer le rôle qu'on attend de lui (J. WAHL sur les pasteurs du Wurtemberg, W. FREITAG sur les curés du doyenné de Vechta); de même, le développement des signes monumentaux ou décoratifs traduit à la fois une plus grande séparation du sacré, et une plus forte implication des laïcs dans sa représentation (U. PFISTER).

3 Ces relations de pouvoir entraînent donc un jeu d'adaptation réciproque entre les " horizons d'attente " des uns et des autres. Les tribunaux ecclésiastiques ruraux de l'évêché de Münster documentent l'évolution constante de ce dialogue : la piété villageoise n'est jamais la même, n'est jamais en vase clos, mais n'est jamais pure docilité (A. HOLZEM). Le mariage calviniste en Lippe (O. BECHER et A. STEINBRECHER), ou l'application des lois sur les naissances illégitimes en Wurtemberg (A. MAISCH) font l'objet d'appropriations inventives : réprimer l'illégitimité accroît ainsi l'illégitimité, qui devient un moyen de forcer la main de parents ou d'un futur récalcitrants. Côté catholique, la définition du miracle et du recours légitimes est, dans son évolution, un bon sismographe des allers-retours entre élites et fidèles ruraux, les jésuites sachant observer la magie "répréhensible » pour en offrir une version " acceptable » (D. SIEBER), les pélerinages (M. FORSTER sur Maria Steinbach) et les miracles (G. LUZ-YGRAF sur la stigmatisation d'Anna Lorger) se situant toujours sur le fil entre ce qui est exalté et ce qui est réprimé.

4 Restait à ouvrir la perspective sur le XIXe s., dont les historiens explorent actuellement la " seconde confessionnalisation ». T. DIETRICH constate, pour des communes de Suisse et du Rhin Moyen, un apaisement (non une disparition) des conflits confessionnels dans la solidarité née des épreuves subies pendant l'ère napoléonienne ; A. GESTRICH souligne la fragmentation des dénominations issues du piétisme wurtembergeois. Mais la pratique religieuse villageoise conserve ses rythmes propres et son " Eigensinn » : l'opposition des villages catholiques intégrés au Wurtemberg en 1803 face aux réformes qui leur sont imposées semble rejouer les résistances aux Lumières catholiques trente ans plus tôt, mais selon une logique, là aussi, reformulée dans un contexte nouveau (V. OSWALT).

L'ensemble est riche et suggestif - mais fallait-il vraiment se priver du concours d'une discipline qui a beaucoup à apprendre aux historiens sur les pratiques religieuses rurales : la Volkskunde (ethnologie)?

Christophe DUHAMELLE 